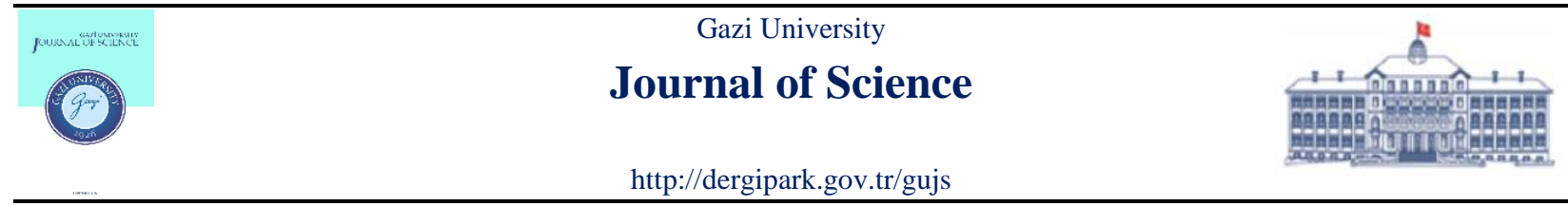

\title{
Manufacturing of Hybrid Yarn Thermoplastic Composites by the Method of Filament Winding
}

\author{
Burcin OZBAY,*(D), Aylin BEKEM ${ }^{(1)}$, Ahmet $\mathrm{UNAL}^{2}(\mathrm{D})$ \\ ${ }^{1}$ Department of Polymer Science and Technology, Istanbul Technical University, 34469 Sariyer, Istanbul, Turkey \\ ${ }^{2}$ Department of Metallurgical and Materials Engineering, Yildiz Technical University, 34210 Esenler, Istanbul, Turkey
}

\section{Highlights}

- Improvement of thermoplastic composites.

- The use of commingled hybrid yarns to overcome fiber-matrix interface problem.

- Production of cylindrical shaped products.

- Modification of filament winding process for thermoplastic matrix.

\section{Article Info}

Received: $30 / 08 / 2018$ Accepted: 11/09/2019

\section{Keywords}

Thermoplastic composites Hybrid yarns

Filament winding

\begin{abstract}
Filament winding is a manufacturing method to produce composite materials with a thermosetting or thermoplastic matrix impregnated continuous fibers. Due to the high melt viscosity of thermoplastics, some problems such as inadequate fiber dispersion in the structure, low wetting ability, and interface quality problems between matrix and fiber might emerge. Preforms can be used in order to solve these problems in the continuous fiber reinforced composite manufacturing; division of the polymer can be made using either powder or fiber form. In this study, polyethylene/E-glass fiber and polypropylene/E-glass fiber hybrid yarns were used as materials to produce thermoplastic composite structures. Firstly, plate samples were produced at various temperatures, periods of time and different thicknesses of ply. After the preparation of samples tensile test, 3 point bending flexural test, and calcination test were applied and Scanning Electron Microscopy (SEM) observations were also performed to these samples, and then the production parameters were optimized. After that, cylindrical shaped samples were produced by a laboratory-type manual filament winding device and ring stiffness tests were performed. According to the test results of the plate samples, the optimum production conditions were determined as $200{ }^{\circ} \mathrm{C}$ for 5 minutes for polyethylene/E-glass fiber composite structure and $220{ }^{\circ} \mathrm{C}$ for 5 minutes for polypropylene/E-glass fiber composite structure. Mechanical test results of plate samples revealed that polypropylene composites presented slightly better results than polyethylene ones. Additionally, in the cylindrical specimens, close results to the ring stiffness values determined by the standards were obtained.
\end{abstract}

\section{INTRODUCTION}

The filament winding method is one of the earliest methods for composite manufacturing developed by Richard E. YOUNG in the 1940s [1,2]. This quite widely used technique is a cost-efficient method especially for mass production. This method is mainly used in hollow, circular or oval sectioned shaped applications such as spherical pressure vessels, pipelines, oxygen and other gas cylinders, rocket motor cases, nozzles, bearings, helicopter propeller blades, large underground storage tanks (e.g. gas, oil, water, acids, alkalis), elbows, T-shaped fittings, etc. [1-3].

It is possible to identify the filament winding method in two techniques: wet and dry winding [4]. Although the traditional filament winding process is thermoset wet winding, it is possible to use thermoset and thermoplastic matrices for the filament winding method. In the wet winding method, monofilament rovings are passed through a resin bath, which contains a low-viscosity liquid resin, wrapped around a rotating mandrel. After finishing the winding step, curing is applied either at room temperature or in an oven to obtain the final product [1,5-6]. On the other hand, thermoplastics require different impregnation methods 
(e.g. in-line thermoplastic direct-impregnation, semi-finished products such as commingled hybrid yarns etc.) than thermosets because of the higher viscosities of thermoplastics [6].

In recent years, usage of thermoplastic composites has increased because of their superiorities over thermosets such as higher fracture toughness, flexibility, shorter and easier processing cycles, and long term storage [7-9]. On the other hand, high melt viscosity of thermoplastic matrices causes inadequate wetting ability of fiber bundles and poor fiber-matrix interface bonding. The impregnation can be a challenging situation in high viscosities; this issue can be improved by decreasing the required distance of the flowing matrix. Mixing the polymer matrix yarns with the reinforcing fiber yarns provides a decreased polymer matrix flow path distance for impregnation. [9,10]. In order to solve impregnation problem, various types of improved techniques such as film stacking, hot melt, film, solution, emulsion, slurry, surface polymerization, commingling and dry powder coating might be selected $[7,11]$.

Commingling process, which is one of the most widely known techniques, performs with two or more continuous multifilament yarns. The structure of hybrid yarns consists of the continuous reinforcing filaments and thermoplastic (matrix) filaments together in fiber forms [12,13]. In this structure, a kind of premixing process is applied to achieve a homogeneous mixture of the matrix and reinforcing fiber. The different sorts of matrix resin forms such as solid state, powder, fiber or fiber bundle, and film state (split films) are commingled with the reinforcing fiber $[12,14]$.

Thanomsilp, and Hogg [15], were studied regarding penetration impact resistance of hybrid composites that were made from commingled yarn fabrics. They used glass/polypropylene, glass/nylon and glass/modified polyethylene terephthalate hybrid fibers, and polyester and epoxy resins. Laminates were manufactured by hand lay-up technique and then put in a hydraulic press. As a result of performed penetration impact testing, there is a modest difference in the total absorbed energy capacity between various combinations of hybrid composites. From their observations, it can be said that the plastic deformation is the major point that advances the absorbing energy of the composites.

Thanomsilp and Hogg [16], were investigated regarding interlaminar fracture toughness of hybrid composites based on commingled yarn fabrics. The same materials were used as in the previous study [15]. GIc and GIIc of laminates were prepared with both polyester and epoxy resins. Mode I interlaminar fracture toughness testing and Mode II delamination resistance tests were performed using a 4-point bend end notch flexure. According to test results, it was observed that the thermoplastic fibers increased the GIc of the laminates but did not have much of an effect on the GIIc values.

The damage tolerance of impact for thermoset composites reinforced with hybrid commingled yarns was researched by Selver et al. [17]. Glass-Polypropylene hybrid yarns with varying proportion of polypropylene fibers (0-35\%) and glass-epoxy thermoset composite were produced. To observe mechanical properties and to interpret the damage resistance and tolerance of the composite structures, tensile test, high energy impact test, low energy impact tests and compression-after-impact tests were done. With respect to the test results, it can be said that tow-level hybridization of glass fibers with polypropylene fibers have weak interface with thermoset matrix. In addition, glass fiber composites showed definite delamination between the plies, which caused marked fiber damage at relatively low impact energies.

Bernet et al. [10], were experimented commingled yarns of reinforcing thermoplastic fibers for rapid processing of complex shapes because of decreasing impregnation time and pressure while processing. They fabricated tubes of braided unidirectional Carbon Fiber/Polyamide 12 commingled yarns using the bladder inflation moulding method. According to their research, they suggested that by using a broad range of yarn architectures and processing techniques, the consolidation model can be worked out.

In our study, the commingled hybrid yarns were preferred for producing a thermoplastic composite structure. There are several novelties of the study. The first novelty of our study is to produce cylindrical shaped products with the filament winding method instead of only producing plate samples from the commingled hybrid yarns. On the other hand, in the literature [15-17], in most of the studies a thermoset 
matrix was also used with commingled yarns. In our study, the filament winding process was performed directly with hybrid yarns without using any additional thermoset matrix.

\section{EXPERIMENTS}

\subsection{Materials and Methods}

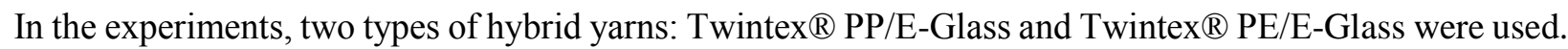
The hybrid yarns were supplied by Tila Composite Domestic and Foreign Trade Ltd. Company. PP/E-Glass hybrid yarn contains a 60 weight percentage of glass fibers (Twintex code: RPP60N265) and PE/E-Glass hybrid yarn material comprises a 65 weight percentage of glass fibers (Twintex code: RPE65N176E). RPP60N265 material has 265 yield in yarn per pound (1872 tex). The average value of the thickness of $\mathrm{PP} / \mathrm{E}-$ Glass commingled yarns is $5.46 \pm 2.2 \mathrm{~mm}$; the mean value of the width is $0.44 \pm 0.09 \mathrm{~mm}$. RPE65N176E material has 176 yield in yarn per pound (2818 tex). The average value of the thickness of $\mathrm{PE} / \mathrm{E}-$ Glass commingled yarns is $7.65 \pm 2.26 \mathrm{~mm}$; the mean value of width is $0.45 \pm 0.08 \mathrm{~mm}$.

These fibers are natural colored, heat and UV stabilized rovings. Manufacturing process comprises of two steps which are manufacturing of plate samples and cylindrical samples fabrication with filament winding method.

\subsection{Manufacturing of Plate Samples}

For the manufacturing of plate samples metal frames, metal plates and a hydraulic press were used. The hydraulic press has two separate pressing compartments as hot and cold. Firstly, hybrid yarn was winded around the metal frame shown in Figure 1. The thickness of this frame is $0.5 \mathrm{~mm}$, with an internal length space of $250 \mathrm{~mm}$, where the sample was formed. The production of the sample was performed in a form of flat plates with the frame. To produce the plate samples at a fixed thickness, this metal frame was used to wrap the fiber. One-ply is formed by wrapping the fiber 10 times on the frame in a strip form. Moreover, to obtain more plies of plate, more than one frame, which are wrapped by fibers, are put one on top of another. In the following figure, one can see the frame in Figure 1A, and wrapped fibers in Figure 1B.

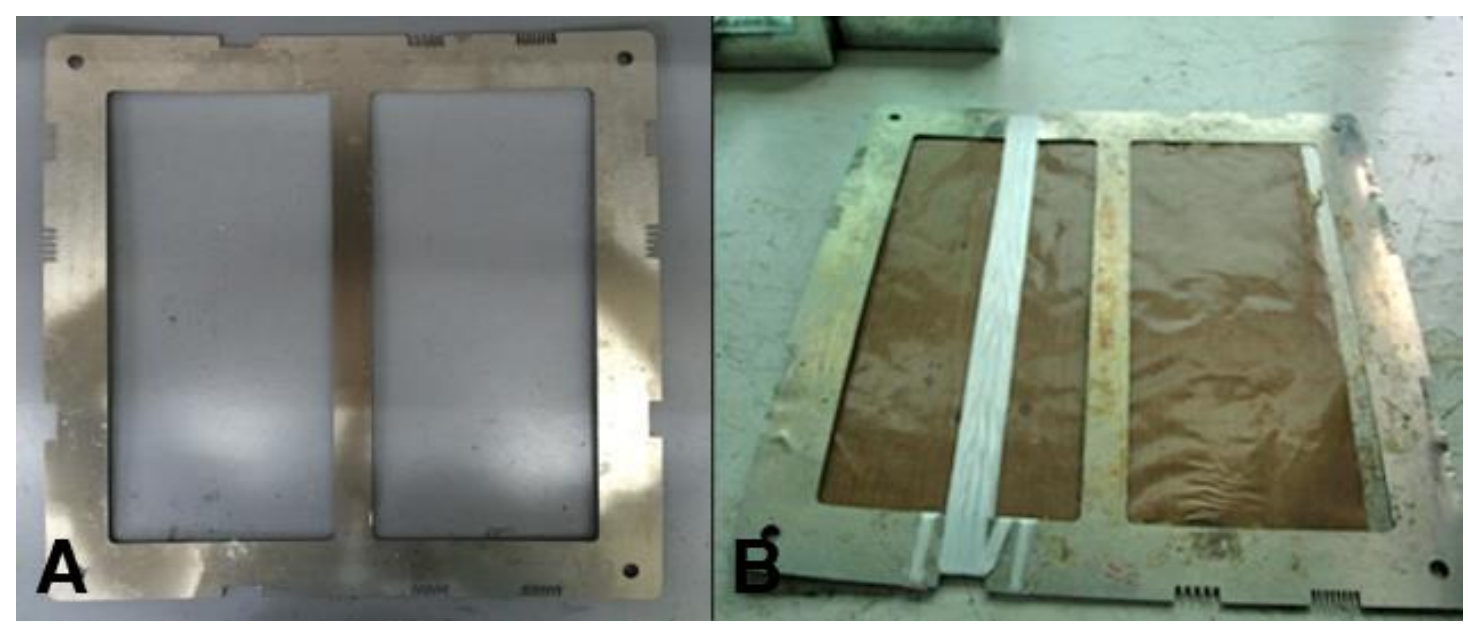

Figure 1. (A) The metal frame (B) Wrapped fibers

After the winding step, the fiber wrapped frame was placed between Teflon coated metal plates, and pressed in the hot zone of the hydraulic press above the matrix melting temperature. The melted matrix covers the reinforcing fiber up and forms the fiber-matrix interface. After the hot press processing, the cold press processing was applied to avoid distortion, which can be formed during solidification. Figure 2 depicts some examples of produce plates. 


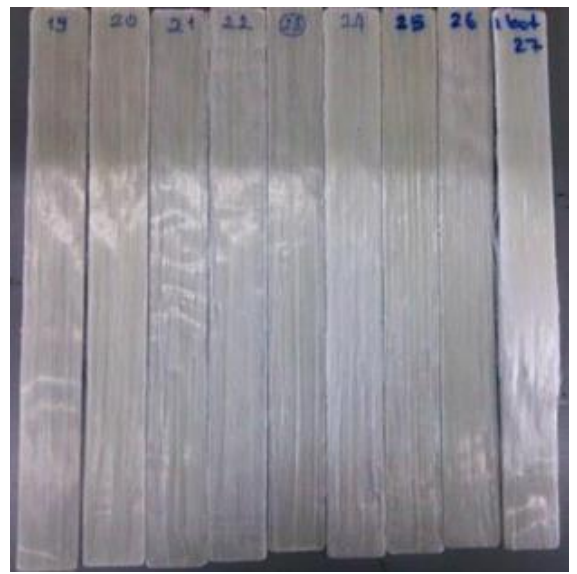

Figure 2. Produced plate samples

In our experiment, different processing times and process temperatures were performed, while the pressure was kept constant at 20 bars. The selected process temperatures were $180{ }^{\circ} \mathrm{C}, 200{ }^{\circ} \mathrm{C}$ and $220{ }^{\circ} \mathrm{C}$; and the process times were 1,3 and 5 minutes. In accordance with these parameters the plate samples were produced. The samples were first subjected to tensile and bending tests, followed by calcination testing.

\subsection{Cylindrical Samples Manufacturing Trials}

The production and testing of the plate samples were evaluated and cylindrical (pipe) shaped sample production was carried out with the manual filament winding device within optimum results. In the production, stainless steel pipe with a diameter of $88.90 \mathrm{~mm}$ was used as a base for cylindrical sample production. First of all, the pipe was placed in the winding device, and covered with Teflon before the winding to avoid any sticking on the base. The hybrid yarns were wrapped around the placed pipe, and heated with the heater to convenient temperatures in the optimized time, which were specified for each hybrid yarn type (PE/E-glass and PP/E-glass). During this winding process, heat was applied to yarns by means of a hot air blower (Liester Triac S) to melt the thermoplastic matrix fiber in the yarns, and to consolidate the yarns in each other to form the pipe shape. When heat is applied, the thermoplastic constituent melts and covers the reinforcing glass fibers. Furthermore, to provide sufficient pressure for the integration of polymer matrix and fiber bundles a $10 \mathrm{~kg}$ metal block was used on the heating step. Figure 3 shows the samples during winding and heating.

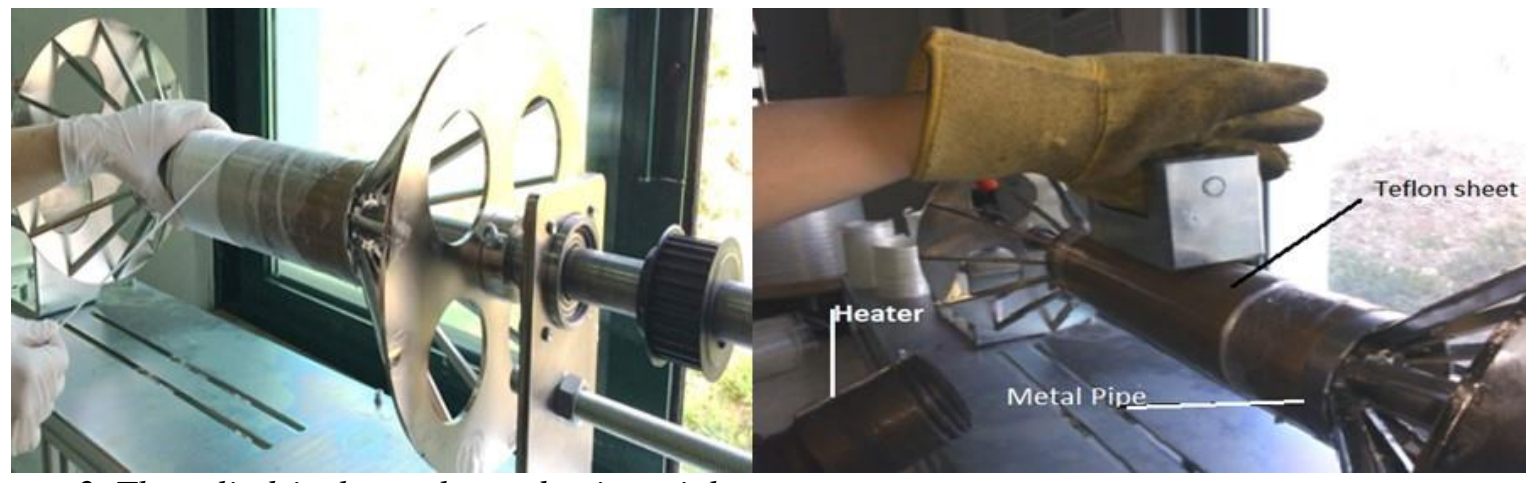

Figure 3. The cylindrical sample production trials

The cylindrical sample production step was followed by the ring stiffness test. The test was applied to the samples which were cut from the completed pipes according to the standard dimensioning. The cylindrical product samples can be seen in Figure 4. 


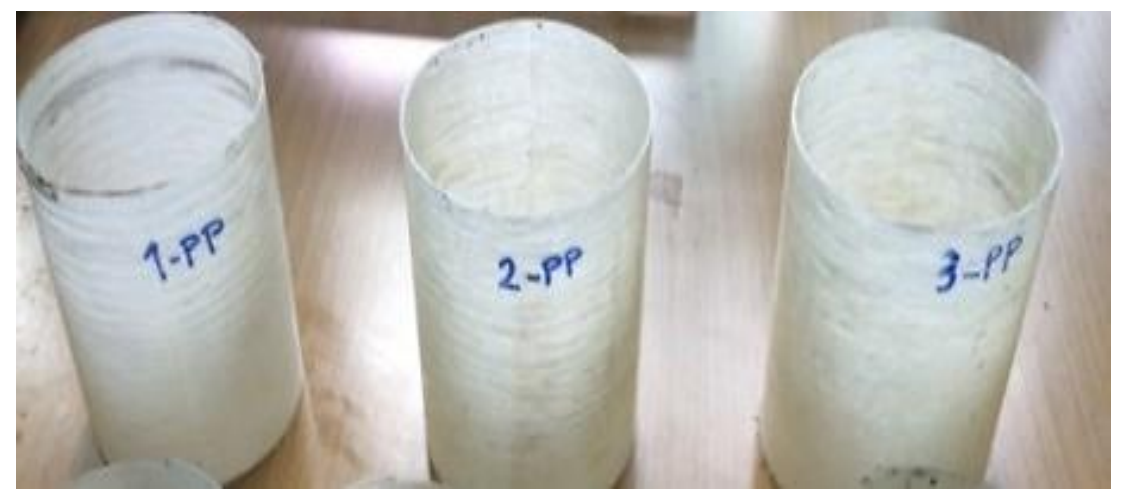

Figure 4. Manufactured cylindrical samples and prepared test specimens

\subsection{Characterization of Produced Composite Structures}

Mechanical Testing Measurement: tensile testing, 3 point bending and ring stiffness tests were conducted with an Instron $336950 \mathrm{kN}$ electromechanical testing machine with appropriate jaw faces. The microstructure of the produced samples was investigated by means of Scanning Electron Microscopy (SEM). In addition, Differential Scanning Calorimetry (DSC) measurements were performed using a DSC Q10 from TA Instrument under nitrogen flow.

All applied tests were conducted at room temperature in accordance with test standards. Tensile, 3 point bending and ring stiffness tests were performed according to BS EN ISO 527-5:2009 [18], BS EN ISO 14125:1998+A1:2011 [19], BS EN 1852-1:2009 [20] (for PP), and BS EN 12666-1:2005+A1:2011 (for PE) [21], respectively. Moreover, a calcination test was applied to determine E-glass volume ratios in the produced composite structures according to ISO 1172:1996 [22].

Tensile test specimens were prepared in accordance with BS EN ISO 527-5:2009-Type B (for longitudinal direction). The test specimens dimensions are as follows: a width of $25 \pm 0,5 \mathrm{~mm}$, an overall length of 250 $\mathrm{mm}$ and a thickness of $2 \pm 0,2 \mathrm{~mm}$. Tensile tests were performed with the test speed of $5 \mathrm{~mm} / \mathrm{min}$. Additionally, bending test specimens were prepared with regard to BS EN ISO 14125:1998+A1:2011-Class III. The bending test specimens' dimensions are a specimen length of $80 \mathrm{~mm}$, an outer span of $64 \mathrm{~mm}$, a width of $15 \mathrm{~mm}$ and $4 \mathrm{~mm}$ thickness. 3 point bending samples were tested at $2 \mathrm{~mm} / \mathrm{min}$. Additionally, as performing ring stiffness test of PP [20] PE [21] and samples, nominal outside diameter $(\mathrm{dn}) \leq 100 \mathrm{~mm}$, which is approximately $90 \mathrm{~mm} .2 \mathrm{~mm} / \mathrm{min}$ test speed was used.

A tensile test could be performed to only one and two-ply plate samples. If the ply number increases, appropriate dimensions of test samples for a tensile test were not able to be extracted. Therefore, the threeply and four-ply flat plate samples were only able to be used for the 3 point bending test. Additionally, microstructure analysis was carried out with a scanning electron microscope (SEM). The fracture surfaces of the samples were observed to determine the type of failure of the composite structure and to examine the interface of the matrix and fiber.

\section{RESULTS AND DISCUSSION}

In thermoplastic composites inadequate fiber dispersion can emerge as a significant issue due to causing problems in the composite structures such as inadequate wetting ability, low interface quality and so on. The basic objective of this study is to see the usability of hybrid yarns (preforms) in filament winding method, and to find a solution to dispersion problem while manufacturing thermoplastic composites.

According to researches, it can be said that the melting temperature range of medium to high density polyethylene is between $125^{\circ} \mathrm{C}$ and $135^{\circ} \mathrm{C}$; for polypropylene it is between $165^{\circ} \mathrm{C}$ and $174{ }^{\circ} \mathrm{C}[23,24]$. The following figures show the differential scanning calorimetry (DSC) analysis of two types of hybrid yarn materials which were used in the experiments. The attained results identify the melting temperature 
of polyethylene to be $126.27^{\circ} \mathrm{C}$ in the PE/E-Glass hybrid yarn (Figure 5) and $160.77{ }^{\circ} \mathrm{C}$; for polypropylene in the PP/E-Glass hybrid yarn (Figure 6), respectively.

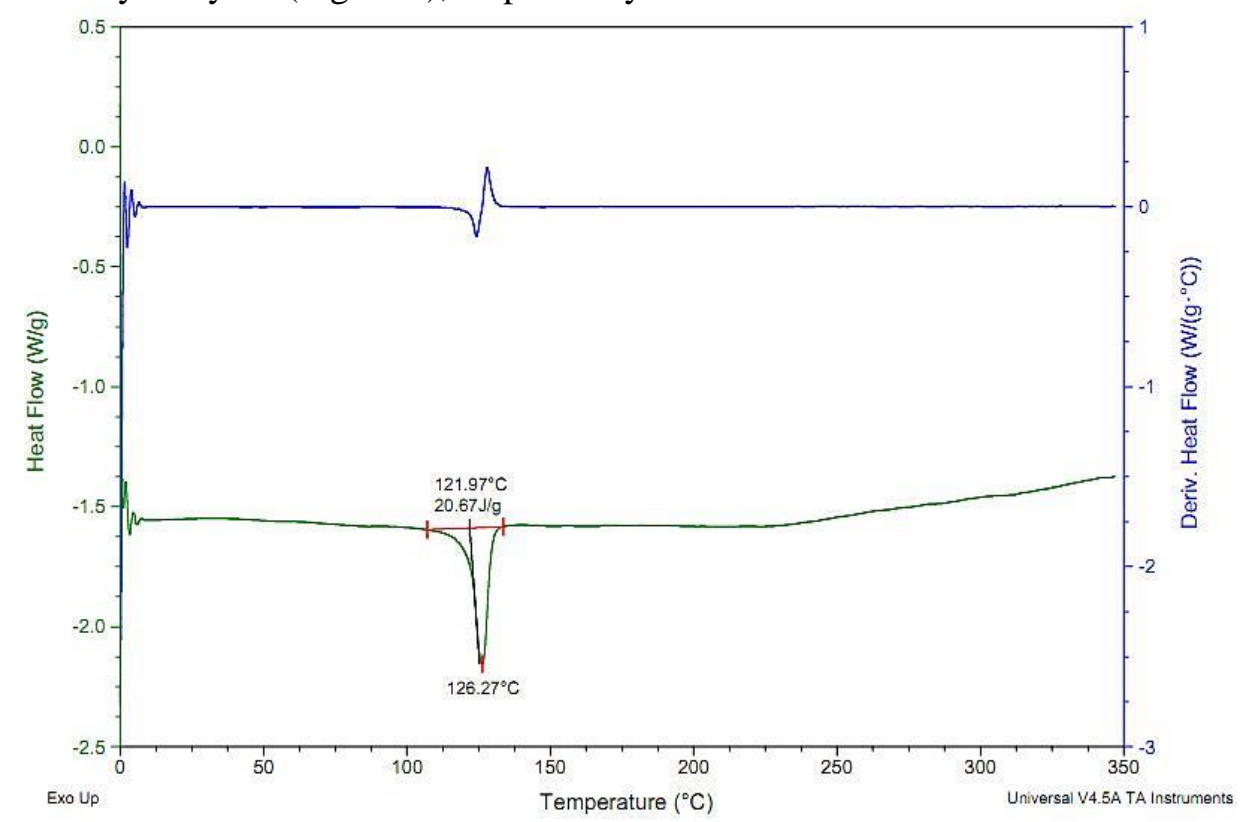

Figure 5. DSC graph of PE/E-Glass hybrid yarn

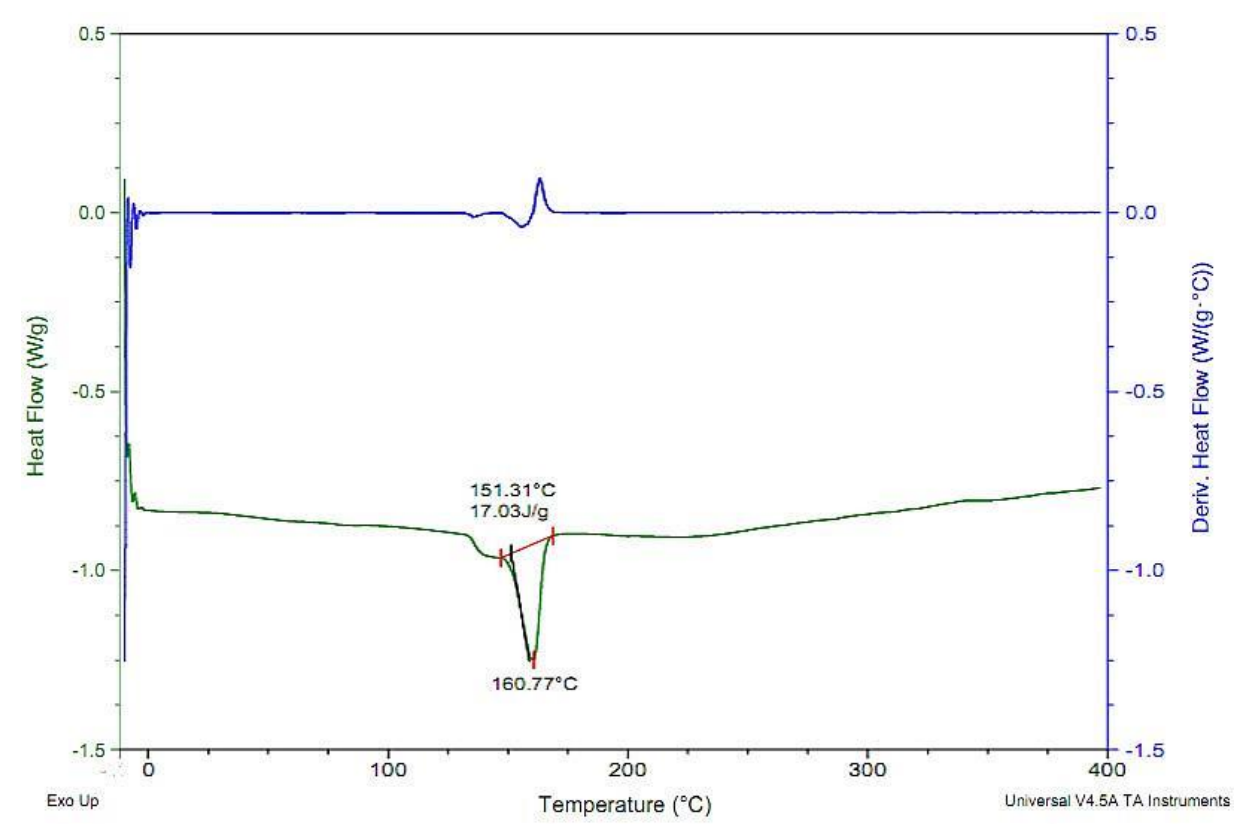

Figure 6. DSC graph of PP/E-Glass hybrid yarn

Primarily, time dependent strength values of the produced plate samples were determined for each of these three temperature groups by applied tensile test, and the averages were calculated. A calcination test was carried out on the produced samples. The results of the calcination tests were so, that the fiber volume ratios were found as about $40 \%\left(\mathrm{~V}_{\mathrm{f}}=40 \%\right)$ for the PE/E-glass hybrid yarn and $34 \%\left(\mathrm{~V}_{\mathrm{f}}=34 \%\right)$ for the PP/Eglass hybrid yarn. In order to detect the optimum temperature and time values, the graphics were drawn, which show the variation of the time-dependent strength values belonging to each temperature group.

In Figures 7 to 10, the optimization curves of the plate samples can be seen together with their standard deviation lines. Figure 7 is PE/E-glass at a ply thickness of one, Figure 8 is PE/E-glass at a ply thickness of two, Figure 9 is PP/E-glass at a ply thickness of one, and Figure 10 is PP/E-glass at a ply thickness of two. On these graphics, T180, T200, T220 represent the applied process temperatures of $180{ }^{\circ} \mathrm{C}, 200{ }^{\circ} \mathrm{C}$ and $220{ }^{\circ} \mathrm{C}$, respectively. 


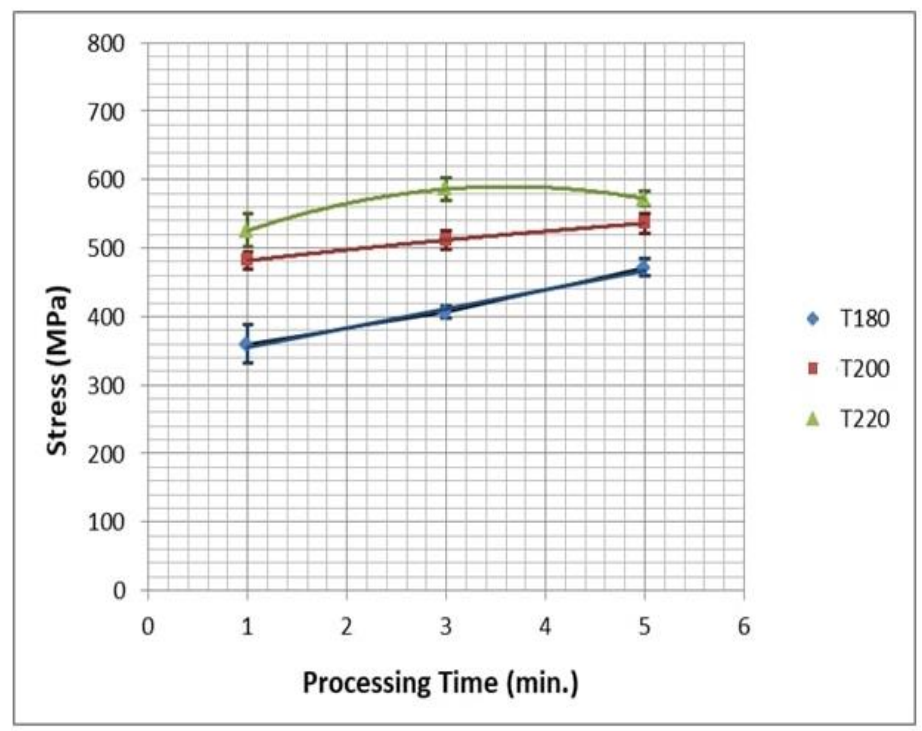

Figure 7. 1 ply PE/E-glass

In Figure 7, the graphic illustrates the strength values of PE/E-glass hybrid yarn specimens consisting of one-ply winding. In all three temperature values, it can be seen that the formed curves are progressing, and reveal an optimum value. It has been observed that the strength values rise with the increasing processing time from 1, 3, and 5 minutes. After this point, if the processing time continues to increase, especially at higher temperature values, excess flow of the matrix occurs, and this situation causes nonhomogeneous fiber distribution. Thus, it could not be possible to obtain samples at high temperature and long processing time values. The samples produced at $180^{\circ} \mathrm{C}$ gave the lowest mechanical values, probably due to the temperature not being high enough to melt the polymer matrix, and surround the fibers appropriately. Additionally, a much longer process time was required for the penetration of the matrix to the fiber at low temperatures. With increasing processing temperature and time, raised strength values were achieved as shown by a decreasing slope in the graphic. At $220{ }^{\circ} \mathrm{C}$, which is the highest operating temperature, the temperature is sufficient for the flow of polymer, so that the matrix melted very fast, and could easily surround the reinforcing fibers. It can be said that a shorter operation time might give more successful results at higher temperatures. Furthermore, the extension of the processing time, and the exposure of the polymer to excessive heat caused a decrease of the mechanical properties. Hence, this is one of the reasons why it could not be possible to obtain appropriate samples at high temperatures for much longer processing time values such as more than 5 minutes.

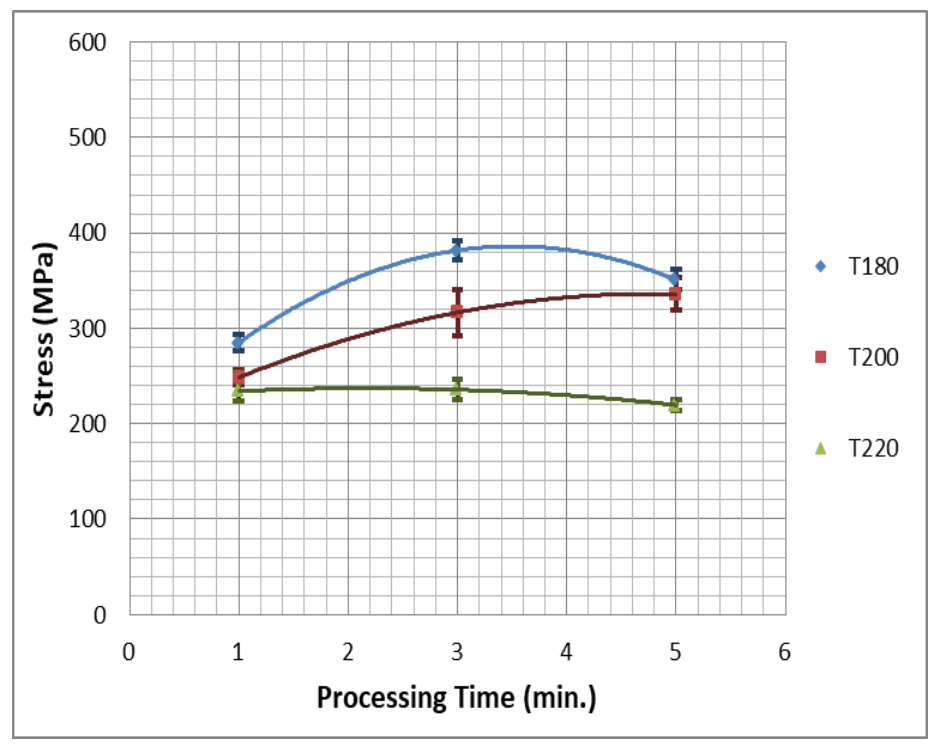

Figure 8. 2 plies of PE/E-glass 
Figure 8 illustrates a graphic which shows the strengths of the specimens with two-ply windings for the $\mathrm{PE} / \mathrm{E}$-glass hybrid yarn. It is observed that the strength values are lower than one-ply samples. This may be due to the deterioration of the fiber orientation between the two plies. The raising temperature for one-ply samples increases the strength values; however, in two-ply samples the strength values decrease with the increasing temperature. The reason for this is the high temperature may deteriorate the fiber orientation by increasing the polymer fluidity. The deteriorating samples could not provide the required strength to the composite structures.

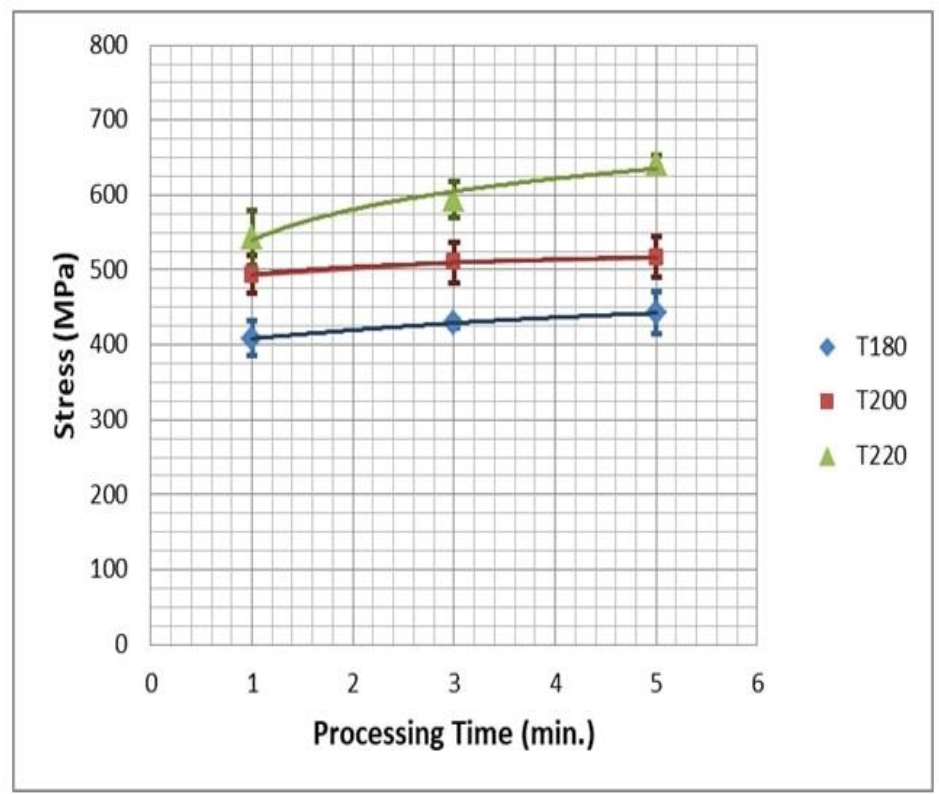

Figure 9. 1 ply PP/E-glass

Figure 9 shows the changing strength values of PP/E-glass hybrid yarn specimens versus increasing processing times consisting of one-ply winding. According to the experiments, the lowest strength value was obtained at a low temperature, similar to PE one-ply plate samples. Moreover, one can also see that there is an increase in strength with increasing temperature. In addition, the strength values are close to each other, even in some cases, they are pretty similar.

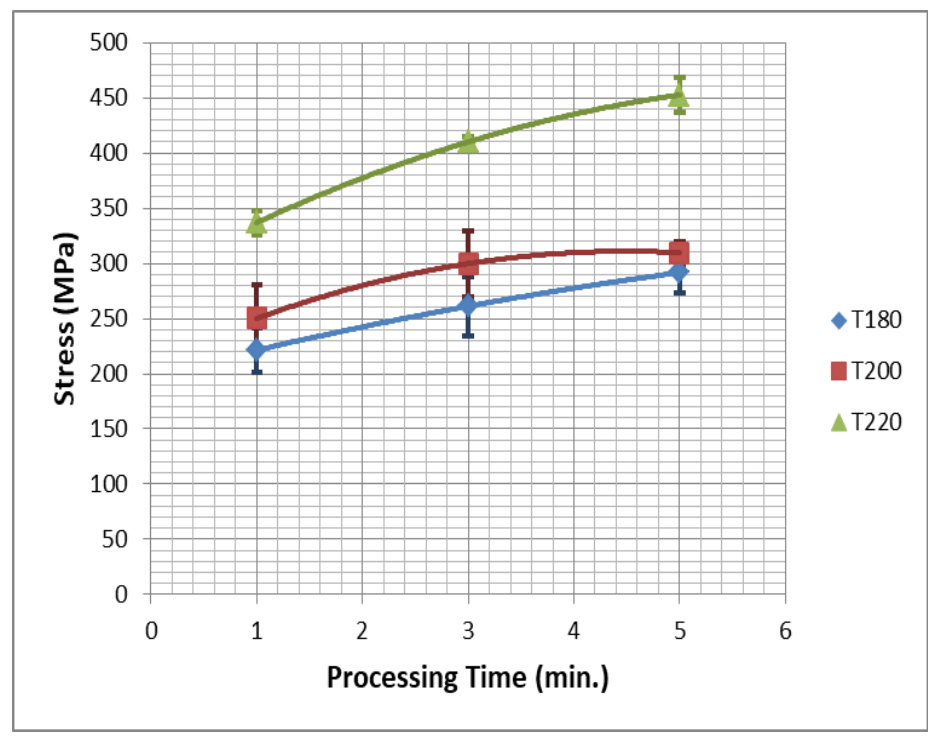

Figure 10. 2 plies of PP/E-glass

Figure 10 contains a graphic of PP samples consisting of two plies winding. It can be seen that the strength values are very low when comparing them with one-ply PP samples. The deterioration of the reinforcing 
fiber orientation may be the reason for the strength reduction in two-ply PP/E-glass. However, two-ply PE samples have increased strength values by increasing processing temperature, contrary to two-ply PP/Eglass. This suggests that the situation in the PE samples may also have been caused by the lack of sufficient heat transfer between the plies.

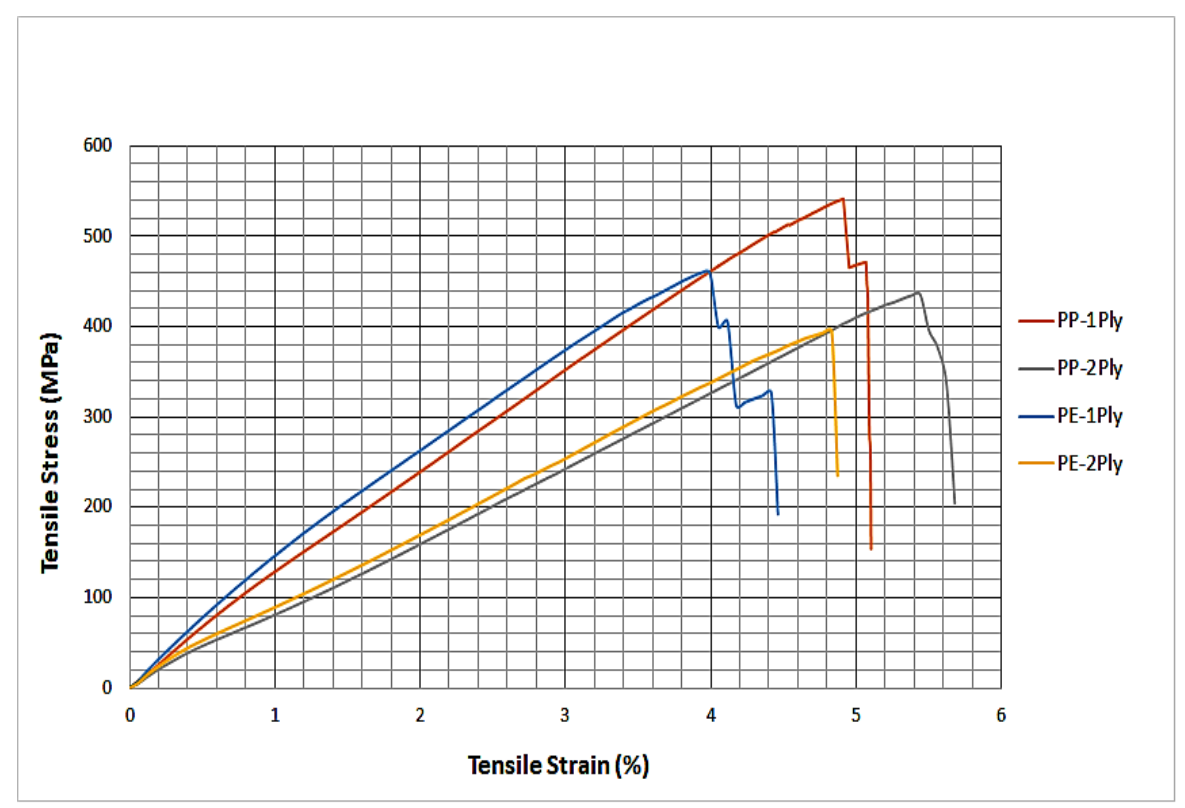

Figure 11. Tensile stress-strain curves of composite samples

In Figure 11, tensile stress-strain curves of some selected PP and PE composite samples were given. Both PP and PE composites had similar trends. With the increase in ply number, strain increased but stress decreased. Proportionally to these trends, slopes of the curves decreased which means lower tensile modulus. Although PP composites had higher stress values, PE composites had a little bit higher tensile modulus. Higher strains of PP composites caused these results.

After tensile test, the 3 point bending test was applied according to standard which is valid for thermoplastic composites. One and two-ply samples could not provide the adequate thickness as required by test standards. Therefore, the bending test could be applied only to the three-ply and four-ply flat plate specimens. (The three and four-ply flat plate specimens for bending test were produced at the optimum processing conditions according to tensile test results). Table 1 depicts the average values of the test results for each group of the 3 point bending test. When the bending stress values at the maximum bending load obtained from the tests are taken into account, one can see that the bending strength increases as the number of plies increases for both PP-E glass hybrid yarn and PE-E glass hybrid yarn samples, respectively. Furthermore, PP-E glass hybrid yarn structures gave better results according to the tensile test results.

Table 1.3 point bending test results of the plate samples

\begin{tabular}{|l|l|l|l|}
\hline & $\begin{array}{l}\text { Bending stress at } \\
\text { maximum bending load } \\
(\mathrm{MPa})\end{array}$ & $\begin{array}{l}\text { Bending strain at } \\
\text { maximum bending load } \\
(\%)\end{array}$ & $\begin{array}{l}\text { Young Modulus } \\
(\mathrm{MPa})\end{array}$ \\
\hline PP-4Ply & 178.8171 & 2.0849 & 11626.46 \\
\hline PP-3Ply & 138.9635 & 1.6469 & 10757.31 \\
\hline PE-4Ply & 134.1728 & 1.6230 & 10656.68 \\
\hline PE-3Ply & 113.6858 & 1.3781 & 10101.23 \\
\hline
\end{tabular}




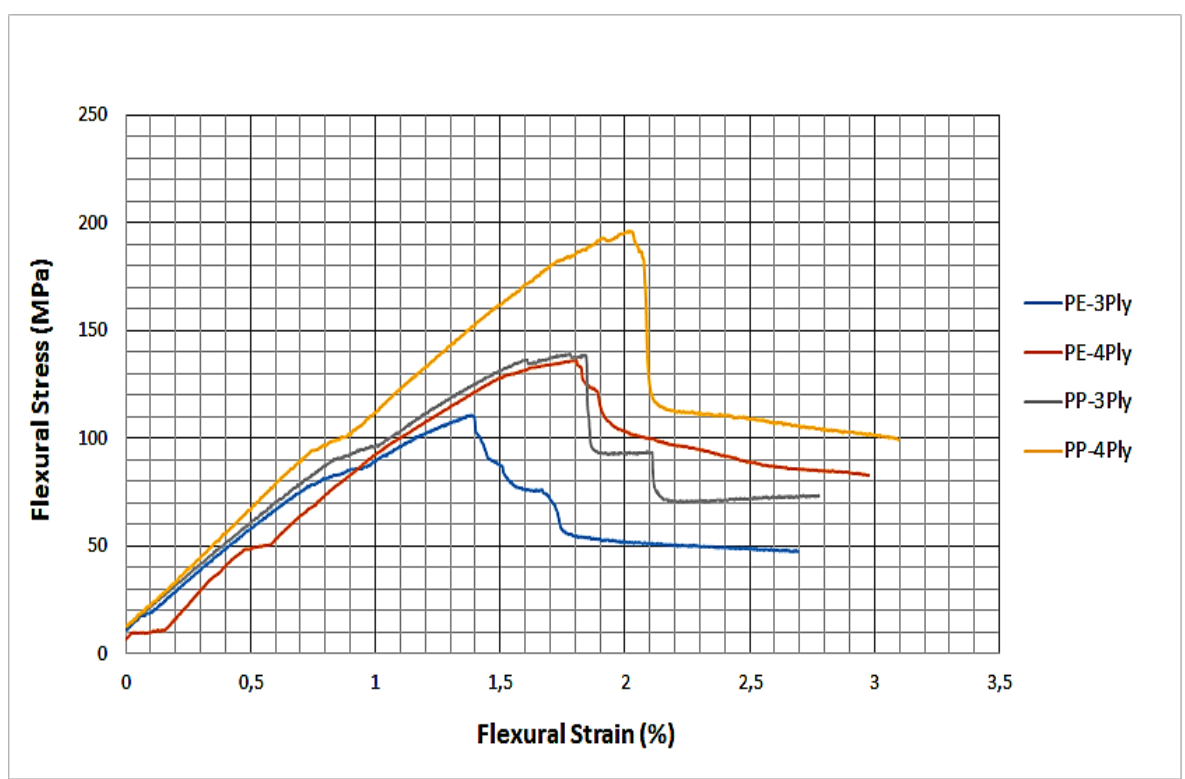

Figure 12. Flexural stress-strain curves of composite samples

In Figure 12, flexural stress-strain curves of some selected PP and PE composite samples were given. Both stress and strain increased with ply increase. Also flexural modulus increased proportionally to these values. The elastic region in all curves ends with fracture. After elastic region, fracture generally progressed step by step which was possibly because of delamination of the plies. PP composite had higher stress, strain and flexural modulus results than PE composites.

Depending on the results, which were obtained from the plate samples, it is determined that the optimum production conditions are 5 minutes at $200{ }^{\circ} \mathrm{C}$ for polyethylene/E-glass material, and 5 minutes at $220{ }^{\circ} \mathrm{C}$ for polypropylene/E-glass material. With these parameters, single ply winding was carried out to produce pipes with a length of approximately $200 \mathrm{~mm}$ and a diameter of $90 \mathrm{~mm}$. The wall thicknesses of the produced pipes are between 0.97-1.23 mm. BS EN 1852-1:2009 [20] and BS EN 12666-1:2005+A1:2011 [21] are standards which are developed for polyethylene and polypropylene unpressurized waste water pipes. Consequently, the average ring rigidity value is around $8 \mathrm{kN} / \mathrm{m}^{2}$ for the sample pipe pieces; the result obtained by a single ply winding which has ca $1 \mathrm{~mm}$ wall thickness. The calculation of the ring stiffness is based on the standard of BS EN ISO 9969:2016 [25]. The ring rigidity results of the cylindrical specimens produced are given in Table 2. PP1,2,3 and PE1,2,3, represent produced PP and PE cylindrical specimens. According to these results, it has been determined that the ring stiffness values of cylindrical samples match the appropriate standard values.

Table 2. Ring stiffness test results of the cylindrical test samples

\begin{tabular}{|l|l|l|l|}
\hline Sample & $\begin{array}{l}\text { F } \\
\text { (Load at 3 \% deflection-kN) }\end{array}$ & $\begin{array}{l}\text { y } \\
\text { (Deflection-mm) }\end{array}$ & $\begin{array}{l}\text { S } \\
\text { (Ring stiffness-kN) }\end{array}$ \\
\hline PP1 & 0.115 & 2.895 & 8.1137 \\
\hline PP2 & 0.118 & 2.989 & 7.8272 \\
\hline PP3 & 0.123 & 2.919 & 8.3976 \\
\hline PP-Average & & & 8.1128 \\
\hline & & & \\
\hline PE1 & 0.134 & 3.030 & 8.3163 \\
\hline PE2 & 0.110 & 2.979 & 7.3878 \\
\hline PE3 & 0.124 & 2.977 & 8.3206 \\
\hline PE-Average & & & 8,0082 \\
\hline
\end{tabular}


In the related studies about non-pressure PP, PE pipes are focuses on mostly durability testing [26,27]. We could find a similar study from Wassenaar [28] about sewerage \& drainage Polypropylene pipes. It was obtained $8 \mathrm{kN} / \mathrm{m}^{2}$ as minimum ring stiffness for pipe diameters between 110 and $800 \mathrm{~mm}$ for between 3.4 and $24.5 \mathrm{~mm}$ wall thickness values. In our study, this value was achieved at a very low wall thickness of approximately $1 \mathrm{~mm}$.

Finally, Figures 13 and 14 show SEM images of cross-sectional areas of the specimens of PE/E glass and $\mathrm{PP} / \mathrm{E}$ glass composite structures after tensile testing. It was observed from the SEM images for both species that the type of damage is fiber pullout. The scattered fibers and the places where these fibers are separated from the structure can be observed in the image. When the upper parts of the broken fiber are examined, it can be clearly seen that their surfaces are surrounded by polymer residues. The results indicate that the fiber-matrix connection is well established at the appropriate production time and layer thickness.

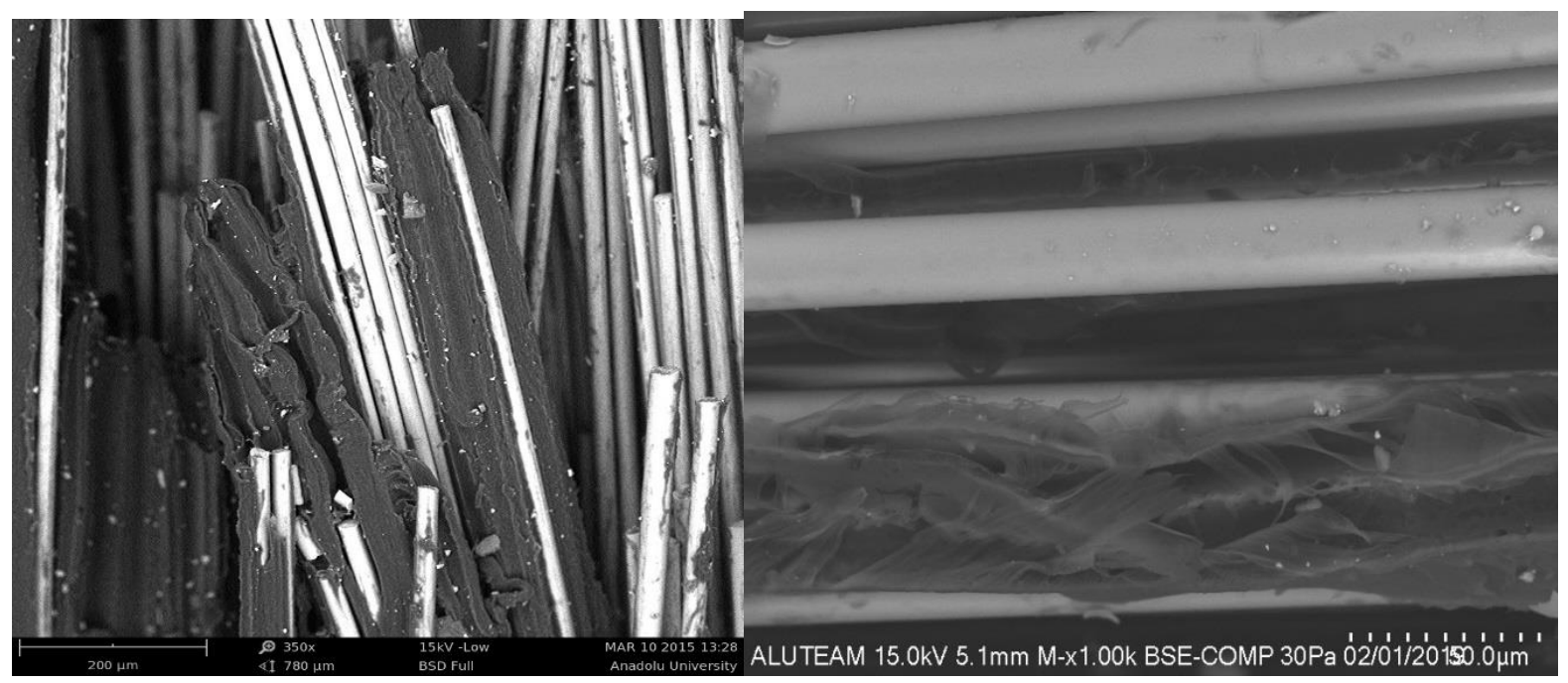

Figure 13. SEM images of produced plate samples-PE/E-glass composite structure

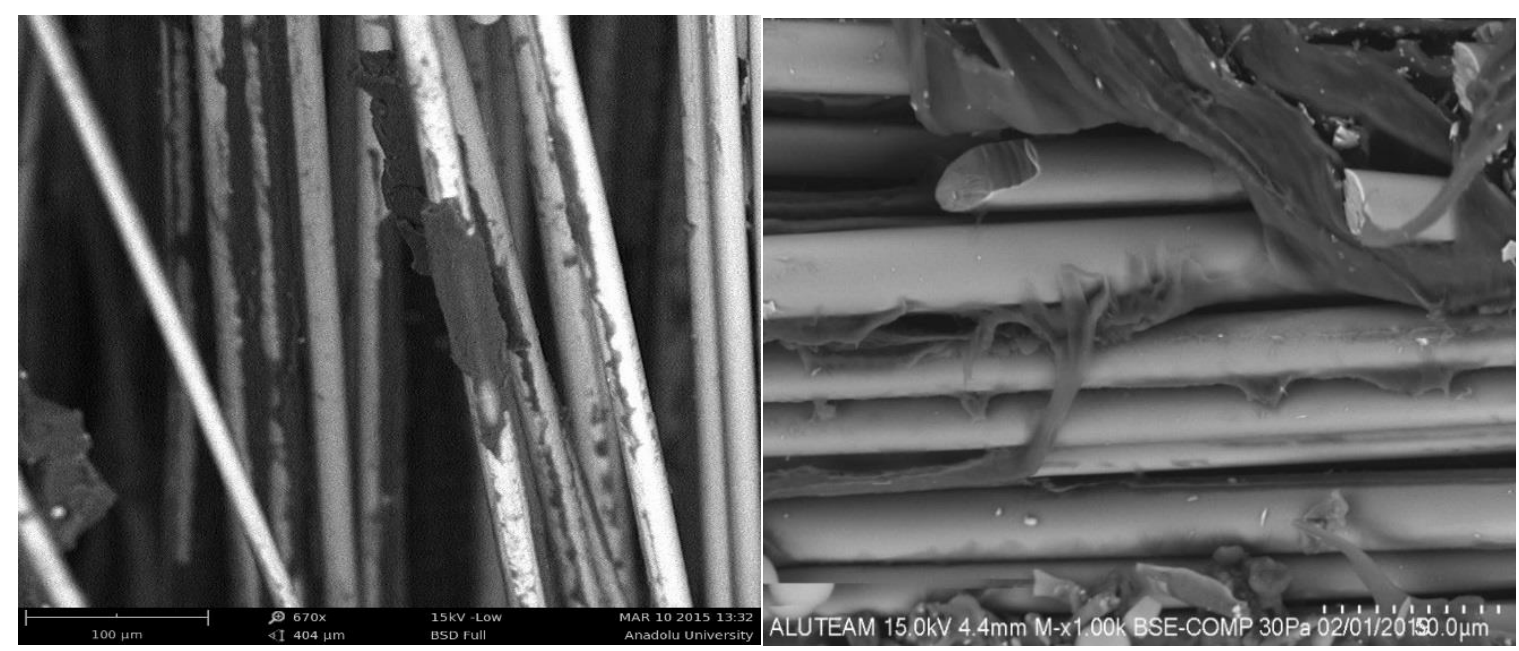

Figure 14. SEM images of produced plate samples-PP/E-glass composite structure 


\section{CONCLUSION}

The aim of this study is to solve the inadequate fiber dispersion, low wetting ability and interface quality problems in thermoplastic composite structures by using commingled hybrid yarns. Another purpose is to analyze the manufacture availability of cylindrical shaped products with hybrid yarns. In this study, higher strength values were obtained for single layers in both polyethylene and polypropylene composites. Moreover, moderately better values were obtained from polypropylene composites than polyethylene ones. While the increase in strength was acquired by increasing the time at low temperatures, higher values were obtained in much shorter periods at high temperatures. Most likely, the reason is that the increased temperature reduces the viscosity of the polymer and increases the fluidity of the matrix. Although, the matrix is well-surrounded by the fibers up to a critical point, after the critical point, the resistance decreases due to excessive flow of the matrix. Finally, it can be said that the produced cylindrical samples meet the requirements of the standards. These values were acquired with in a single layer winding and a very low wall thickness of approximately $1 \mathrm{~mm}$.

\section{ACKNOWLEDGEMENTS}

This study was supported by MIR Research \& Development Co. and Aluminum Test Training and Research Center (ALUTEAM) of Fatih Sultan Mehmet Vakif University.

\section{CONFLICTS OF INTEREST}

No conflict of interest was declared by the authors.

\section{REFERENCES}

[1] Zu, L., "Design and Optimization of Filament Wound Composite Pressure Vessels", MSc. Thesis, Delft University of Technology, Delft, 1-27, (2012).

[2] Green, J. E., Composite Filament Winding, Peters S.T., ASM International, Ohio, (2011).

[3] Friedrich, K., Polypropylene an A-Z reference 1 st. ed., J., Kluwer Academic Publishers, UK, 81-87, (1999).

[4] Schwartz, M. M., Composite Materials, Volume II: Processing, Fabrication, and Applications, Springer-Verlag, Berlin, 15-17, (2017).

[5] Mallick, P. K., Fiber Reinforced Composites Materials, Manufacturing and Design, 3rd ed., CRC Press, Dearborn, Michigan, 408-416, (2007).

[6] Schuster, J., Duhovic, M., Bhattacharyya, D., Manufacturing and Processing of Polymer Composites, Bhattacharyya, D., Fakirov, S., Carl Hanser Verlag, Munich, 10-15, (2012).

[7] Grouve, W. J. B., Akkerman, R., "A consolidation process model for film-stacking glass/pps laminates", 17th International Conference on Composite Materials, Edinburgh, (2009).

[8] Svensson, N., Shishoo, R., Gilchrist, M., "Manufacturing of thermoplastic composites from commingled yarns-a review", Journal of Thermoplastic Composite Materials, 11: 22-56, (1998).

[9] Risicato J.-V., Kelly F., Soulat D., Legrand X., Trümper W., Cochrane C., Koncar V., "A complex shaped reinforced thermoplastic composite part made of commingled yarns with integrated sensor", Applied Composite Materials, 22 (1): 81-98, (2015).

[10] Bernet, N., Michaud, V., Bourban, P-E., Manson, J-A. E., "Commingled yarn for rapid processing of complex shapes", Composites Part A: Applied Science and Manufacturing, 32: 1613-1626, (2001). 
[11] Alagirusamy, R., Das A., Technical Textile Yarns Industrial and Medical Applications, 1 st ed., Woodhead Publishing, Cambridge, (2010).

[12] Mankodi, H. R., Specialist Yarn and Fabric Structures Developments and Applications, Gong, R. H., Woodhead Publishing, Cornwall, (2011).

[13] Lauke, B., Bunzel, U., Schneider, K., "Effect of hybrid yarn structure on the delamination behaviour of thermoplastic composites", Composites Part A: Applied Science and Manufacturing, (29): 13971409, (1998).

[14] Choi, B.-D., Diestel, O., Offermann, P., "Commingled CF/PEEK Hybrid Yarns for Use on Textile Reinforced High Performance Rotors", ICCM International Committee on Composite Materials, Paris, (2000).

[15] Thanomsilp, C., Hogg, P.J., "Penetration impact resistance of hybrid composites based on commingled yarn fabrics", Composites Science and Technology, 63: 467-482, (2003).

[16] Thanomsilp, C., Hogg, P.J., "Interlaminar fracture toughness of hybrid composites based on commingled yarn fabrics”, Composites Science and Technology, 65:1547-1563, (2005).

[17] Selver, E., Potluri, P., Hogg, P, Soutis, C., Impact damage tolerance of thermoset composites reinforced with hybrid commingled yarns, Composites Part B, 91:522-538, (2016).

[18] International Organization for Standardization (ISO). ISO 527-5 (2009) Plastics-Determination of Tensile Properties-Part 5: Test Conditions for Unidirectional Fibre-Reinforced Plastic Composites. https://www.iso.org/standard/52991.html. Publication date: July 2009. Access date: 04.02.2018.

[19] British Standards Institution (BSI). BS EN ISO 14125 (1998+A1:2011). Fibre-Reinforced Plastic Composites. Determination of Plexural Properties. https://shop.bsigroup.com/ProductDetail/?pid=000000000030219524. Publication date: June 1998. Access date: 05.02.2018.

[20] British Standards Institution (BSI). BS EN 1852-1 (2009) Plastics Piping Systems for Non-Pressure Underground Drainage and Sewerage. Polypropylene (PP). https://shop.bsigroup.com/en/ProductDetail/?pid=000000000030165578. Publication date: April 2009. Access date: 10.12.2017.

[21] British Standards Institution (BSI). BS EN 12666-1 (2005+A1:2011) Plastics Piping Systems for NonPressure Underground Drainage and Sewerage Polyethylene (PE). https://shop.bsigroup.com/en/ProductDetail/?pid=000000000030216631. Publication date: January 2006. Access date: 12.12.2017.

[22] British Standards Institution (BSI). BS EN ISO 1172 (1996) Textile-Glass-Reinforced PlasticsPrepregs, Moulding Compounds and Laminates-Determination of The Textile-Glass and MineralFiller Content-Calcination Methods. https://www.iso.org/standard/5750.html. Publication date: December 1996. Access date: 05.02.2018.

[23] Ebewele, R. O., "Polymer Science and Technology”, CRC Press LLC, Florida, 419-469, (2000).

[24] Carraher, C. E., Jr., "Polymer Chemistry”, 6 th Ed., Marcel Dekker, Inc., Florida, (2003).

[25] BS EN ISO 9969 (2016), “Thermoplastics Pipes. Determination of Ring Stiffness”, London, UK: BSI.

[26] Thörnblom, K., Nilsson, S. F., Sällberg, S.-E. , Bergström, G., "Durability of non-pressure polypropylene pipe materials, sp building technology and mechanics", SP REPORT 2007:30, Göteborg, (2007). 
[27] Bergström, G., Nilsson, S., Thörnblom, K., Ek, C.-G., Herbst H., Stenström A., "Durability Testing for 100 Year Lifetime For Buried Non-Pressure Plastic Pipes", Swedish National Testing and Research Institute, Sweden, (2006).

[28] Wassenaar, J., "Polypropylene materials for sewerage \& drainage pipes with reduced energy and carbon footprints", Journal of Materials Science and Engineering B, 6, (11-12):283-290, (2016). 